\title{
The Soviet Military Plan of Tokyo (1966)
}

\author{
Alexander J. Kent \\ Canterbury Christ Church University, alexander.kent@canterbury.ac.uk
}

Keywords: Soviet maps, city plans, history of cartography, secret maps

\begin{abstract}
:
As part of its secret Cold War mapping programme, the Soviet Union produced detailed plans of over 2,000 towns and cities within foreign territories around the globe. Some of these maps were made available for the first time in 1993 at the $16^{\text {th }}$ International Cartographic Conference in Cologne, Germany, via a Latvian map dealer who discovered them at an abandoned depot outside Riga as the Red Army withdrew. However, Soviet city plans have only recently become the topic of cartographic research, which has provided some insights into aspects of their production, accuracy and purpose, that continue to have relevance for mapping diverse urban environments today.

This paper focuses on the city plan of Tokyo, which comprises four sheets and was produced by the General Staff of the Soviet Union in 1966. Street names are transcribed to allow phonetic pronunciation and the plan identifies almost 400 important objects (from factories to hospitals), which are described in a numbered list. Although the street-level detail of the plan is produced according to a standard specification and symbology, it adopts an uncommon scale of 1:20,000 (with contours at 5-metre intervals) and incorporates an unusual and transitory cartographic style in the history of the series.

In addition to highlighting the main features of the plan and exploring some possible sources, this paper interprets the wider context of the Soviet military plans of Japanese towns and cities (over 90 are known to have been mapped during the Cold War). Aside from their historical significance, it suggests how understanding the city plans can reveal how problems of the design and portrayal of detailed topographic information may be overcome through their unfamiliar, yet comprehensive, cartographic language.
\end{abstract}

